\title{
TEMPORARY REMOVAL: Acarine attractants: Chemoreception, bioassay, chemistry and control
}

\author{
Ann L. Carr, R. Michael Roe*
}

Department of Entomology, Campus Box 7647, North Carolina State University, Raleigh, NC27695-7647, USA

The publisher regrets that this article has been temporarily removed. A replacement will appear as soon as possible in which the reason for the removal of the article will be specified, or the article will be reinstated.

The full Elsevier Policy on Article Withdrawal can be found at

http://www.elsevier.com/locate/withdrawalpolicy.

* Corresponding author. Tel.: +1919515 4325; fax: +1919515 7746.

E-mail address: michael_roe@ncsu.edu (R. Michael Roe). 